\title{
Novel freeze-casting device with high precision thermoelectric temperature control for dynamic freezing conditions
}

\author{
Christiansen, Cathrine Deichmann; Nielsen, Kaspar Kirstein; Bjørk, Rasmus
}

Published in:

Review of Scientific Instruments

Link to article, DOI:

$10.1063 / 1.5134737$

Publication date:

2020

Document Version

Publisher's PDF, also known as Version of record

Link back to DTU Orbit

Citation (APA):

Christiansen, C. D., Nielsen, K. K., \& Bjørk, R. (2020). Novel freeze-casting device with high precision thermoelectric temperature control for dynamic freezing conditions. Review of Scientific Instruments, 91(3), [033904]. https://doi.org/10.1063/1.5134737

\section{General rights}

Copyright and moral rights for the publications made accessible in the public portal are retained by the authors and/or other copyright owners and it is a condition of accessing publications that users recognise and abide by the legal requirements associated with these rights.

- Users may download and print one copy of any publication from the public portal for the purpose of private study or research.

- You may not further distribute the material or use it for any profit-making activity or commercial gain

- You may freely distribute the URL identifying the publication in the public portal 


\section{Novel freeze-casting device with high precision thermoelectric temperature control for dynamic freezing conditions}

Cite as: Rev. Sci. Instrum. 91, 033904 (2020); https://doi.org/10.1063/1.5134737

Submitted: 01 November 2019 . Accepted: 19 February 2020 . Published Online: 05 March 2020

Cathrine D. Christiansen (D), Kaspar K. Nielsen (D), and Rasmus Bjørk (D)
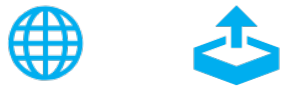

\section{ARTICLES YOU MAY BE INTERESTED IN}

Novel ring-type measurement system of shear yield stress for magnetorheological fluid under high temperature

Review of Scientific Instruments 91, 035105 (2020); https://doi.org/10.1063/1.5128582

Application of stereovision on a saddle-shaped membrane structure in aero-elastic wind tunnel test

Review of Scientific Instruments 91, 035104 (2020); https://doi.org/10.1063/1.5137757

An electromagnetic separation system for the enrichment of ${ }^{39} \mathrm{Ar}$

Review of Scientific Instruments 91, 033309 (2020); https://doi.org/10.1063/1.5128697

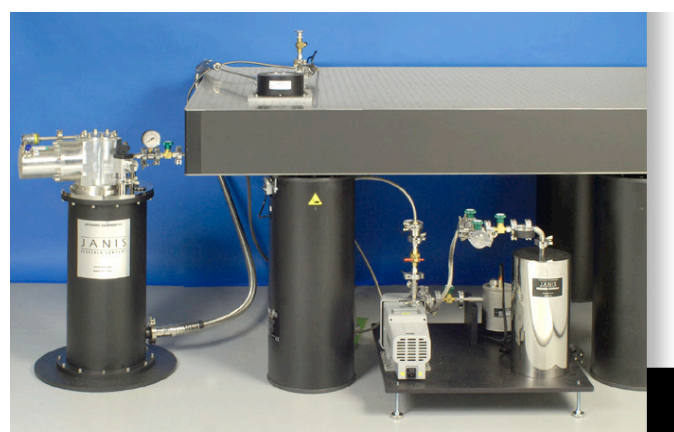

sales@janis.com

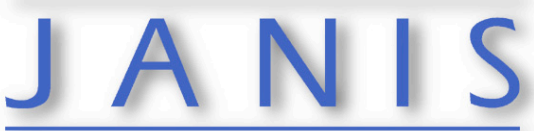

Rising LHe costs? Janis has a solution. Janis' Recirculating Cryocooler eliminates the use of Liquid Helium for "wet" cryogenic systems. 


\title{
Novel freeze-casting device with high precision thermoelectric temperature control for dynamic freezing conditions
}

\author{
Cite as: Rev. Sci. Instrum. 91, 033904 (2020); doi: 10.1063/1.5134737 \\ Submitted: 1 November 2019 • Accepted: 19 February 2020 • \\ Published Online: 5 March 2020

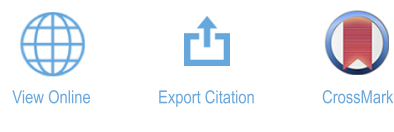

Cathrine D. Christiansen, (D) Kaspar K. Nielsen, (D) and Rasmus Bjørk ${ }^{\text {(b) }}$ (D)

AFFILIATIONS
Department of Energy Conversion and Storage, Technical University of Denmark, Anker Engelundsvej 1,
DK-2800 Kgs. Lyngby, Denmark

a) Author to whom correspondence should be addressed: cadech@dtu.dk

${ }^{\text {b) }}$ Electronic mail: rabj@dtu.dk

\begin{abstract}
A novel freeze-casting device utilizing a thermoelectric element for high precision temperature control allowing for dynamic freezing conditions of freeze-cast materials is presented. Freeze-casting is a processing route for producing materials of anisotropic porosity in the form of aligned and well-defined microchannels. In freeze-casting, particulates of a material are suspended in a fluid and a thermal gradient is applied across for directional freezing. Controlling the thermal gradient across the suspension amounts to controlling the kinetics and freezing direction in the suspension and thus the resulting structural features and dimensions of the microchannels. The performance of the device presented here was evaluated by directional freezing of both water and aqueous ceramic suspension samples using both linear and exponential freezing profiles. The freezing front was successfully tracked by continuously measuring the temperature gradient along the sample using thermocouples directly mounted on the freeze-casting mold. The current minimum operational temperature of the freeze-caster is $\sim 220 \mathrm{~K}$, with freezing front velocities in the range of $\sim 5 \mu \mathrm{m} / \mathrm{s}$ to $30 \mu \mathrm{m} / \mathrm{s}$ for sample lengths of $5 \mathrm{~mm}-25 \mathrm{~mm}$.
\end{abstract}

Published under license by AIP Publishing. https://doi.org/10.1063/1.5134737

\section{INTRODUCTION}

Freeze-casting presents a processing route for engineering of microchannels in various materials. Freeze-cast materials have anisotropic porosity in the form of aligned and well-defined macropores, i.e., microchannels. The alignment of porosity ensures porous materials of enhanced mechanical strength and flow properties in the direction of the microchannels, making these materials advantageous for biomedical applications, ${ }^{1}$ filters, ${ }^{2}$ and catalytic support structures. ${ }^{3,4}$ For a broader scope of the recent applications and materials used in freeze-casting, refer to the work of Deville.

Freeze-casting, or ice-templating, is a novel templating technique based on the anisotropic growth of ice crystals in aqueous suspensions of a particulate material upon directional freezing. This is achieved by bringing one side of the suspension into contact with cooling source, thus creating a thermal gradient across the suspension. When ice crystals grow in a suspension with an appropriate thermal gradient, they cause a segregation of material particles resulting in a two-phase body of ice and material. Removing the ice by sublimation results in a structure with anisotropic porosity in the form of directional macropores where the ice used to be present. The dimensions of the macropores thus depend on the size of the ice crystals and are typically of the order $\sim 1 \mu \mathrm{m}$ to $\sim 100 \mu \mathrm{m} .{ }^{3,6-8}$ Moreover, the morphology of the pores strongly depends on the freezing conditions; most notably is the conclusion that the faster the freezing front moves, the narrower the resulting channels will be.

We adopt here the following definition of the freezing front: at any time during the freezing, a cross section of the suspension will undergo the transformation from the liquid to the solid state and the speed of this front is the freezing front velocity. The cross section need not be flat and will, in some cases, show a degree of curvature due to the mold boundary condition, i.e., the mismatch between thermal conductivity of the solid phase, liquid phase, and mold material, as shown by in situ $\mathrm{x}$-ray radiography. 
Controlling the thermal gradient across the suspension amounts to controlling the kinetics, i.e., the freezing front velocity, and freezing direction in the suspension and thus the resulting structural features and dimensions. The thermal gradient partly depends on the temperature of the cooling source but can largely be controlled by the temperature of the cooling source under constant ambient conditions. High precision temperature control of the cooling source coupled with high spatial resolution temperature monitoring is therefore crucial in the engineering of materials by freeze-casting.

For the constant temperature of the cooling source, the growing solid part of the suspension will act as an increasing thermal resistance, slowing down the freezing front velocity. The constant temperature of the cooling source therefore leads to graded structures of varying pore sizes. ${ }^{8,11}$ The pore size has been shown to depend directly on the freezing front velocity with approximately constant freezing front velocities yielding nearly homogeneous channel sizes throughout the freeze-cast structures. ${ }^{7,12}$ However, to achieve a constant freezing front velocity, dynamic freezing conditions must be implemented to counteract the increasing thermal resistance from the frozen body. Various dynamic temperature profiles of the cooling source during freeze-casting have been tested, where both linear, ${ }^{3,6-8}$ exponential, ${ }^{13-15}$ and parabolic ${ }^{10}$ freezing functions significantly increased the homogeneity of structural features and dimensions of microchannels throughout the sample length.

However, implementation of temperature profiles for freezing control as well as measures for monitoring of freezing conditions poses specific requirements for the design of a freeze-casting device.

\section{A. Designing a freeze-casting device}

In all its simplicity, all that is required for a functioning freezecaster is a cooling source, i.e., a thermal reservoir with a temperature below the suspension solidification temperature. A container that keeps the suspension such that only one side is brought into thermal contact with the cooling source is then mounted on the reservoir. In this way, a thermal gradient is created throughout the suspension, which is also isolated from the ambient.

The cooling source most often consists of a liquid refrigerant brought into thermal contact with a cold finger or a plate of a material with large thermal conductivity. ${ }^{1,3,4,13,15,16}$ In the most common freeze-casting setup, a copper rod is immersed directly into a container of liquid nitrogen. Temperature control of the nonimmersed end of the rod is then achieved by either varying the level of nitrogen in the container ${ }^{3}$ or by a heating sleeve installed at the top of the rod typically equipped with a thermocouple and proportional-integral-derivative (PID) control. ${ }^{1,3,4,13,15,16}$ In such a setup, one side of a suspension contained in a mold can be brought into contact with the copper rod. This type of setup is thus referred to as a one-sided setup.

With the implementation of an additional cooling source at the opposite side of the freezing suspension, in a so-called doublesided setup, ${ }^{6,7,12}$ full thermal control across the sample and thus of the thermal gradient is achieved, however, with difficulties arising from the expansion of the freezing suspension. Bidirectional freezing can be achieved by various mold-altering approaches, e.g., by the introduction of an insulating wedge between the cooling source and the suspension ${ }^{16}$ or by using a mold with an additional cooling side perpendicular to the cooling source. ${ }^{17}$ Bidirectional freezing imposes a second thermal gradient on the freezing suspension and thus additional ordering of the channel orientations in the plane perpendicular to the freezing direction. Furthermore, the ordering of the structural and material gradients in the final freeze-cast can be altered with rotational freezing for the fabrication of tubes, ${ }^{18}$ freezing in magnetic- ${ }^{1,19}$ and electrostatic ${ }^{19}$ fields, and tape-freeze casting.

Designing a freeze-casting device is all about controlling the freezing conditions, common for all freeze-casting setups is therefore the need for a cooling source with temperature control. While the liquid refrigerant for the aforementioned setups is typically in the form of volatile liquid nitrogen or ethanol, a thermoelectric element where the applied voltage determines the temperature represents an alternative cooling source, ${ }^{21,22}$ although, thus far, thermoelectric elements have only been implemented for processing of freeze-cast structures under static cooling conditions. Furthermore, a possibility of tracking the freezing front is desired. Tracking of the freezing front can be done visually by using a see-through mold made from acrylic glass and equipped with a scale bar. ${ }^{3,7}$ However, this requires a clear visual distinction between the solid phase and the liquid phase, which is not always the case. ${ }^{23}$ Temperature measurements of the freezing suspension, either by attaching thermocouples ${ }^{15}$ or by the use of thermal infrared imaging, ${ }^{24}$ pose an alternative tracking method granted that the exact solidification temperature of the suspension is known. The solidification temperature of the suspension moreover defines the desired working range of the freeze-casting setup. In this work, the freeze-casting device is optimized for aqueous suspensions as water is easily accessible and exerts a low vapor pressure at STP, and thus, no precautions against fluid evaporation are necessary in the experimental setup. With a solidification temperature of $273.15 \mathrm{~K}$ for pure water, the desired operational temperature span of the freeze-caster must therefore be in a range around this temperature.

Here, we present a custom-built freeze-casting device with thermoelectric temperature control for the implementation of dynamic freezing conditions in combination with a novel interchangeable mold design using temperature measurements for tracking the freezing front.

\section{FREEZE-CASTING DEVICE}

The freeze-casting device is shown in Fig. 1. The central part of the freeze-caster is contained within the vacuum chamber (A) where the thermoelectric unit (Peltier element) for temperature control is shown in the zoomed-in view of Fig. 2. The thermoelectric unit is powered by a power supply (Aim-TTi CPX 400SP) (D). A Pfeiffer turbo pump (Hicube $80 \mathrm{ECO}$ ) (F) is run during operation, keeping the pressure inside the vacuum chamber at $10^{-4}$ mbar to avoid condensation and to ensure proper performance, while a Julabo temperature bath (CF 40) $(\mathrm{G})$ is connected to a heat sink on which the Peltier element is mounted. A personal computer (PC) (C) is connected, which runs the control software and logs temperature measurements from the Keithley (2700 DMM, with scanner card 7700) (E).

In Fig. 2, the details of the device are provided. Inside the vacuum chamber, (A) is a $\mathrm{Cu}$ cold-finger (E) mounted on a Peltier 


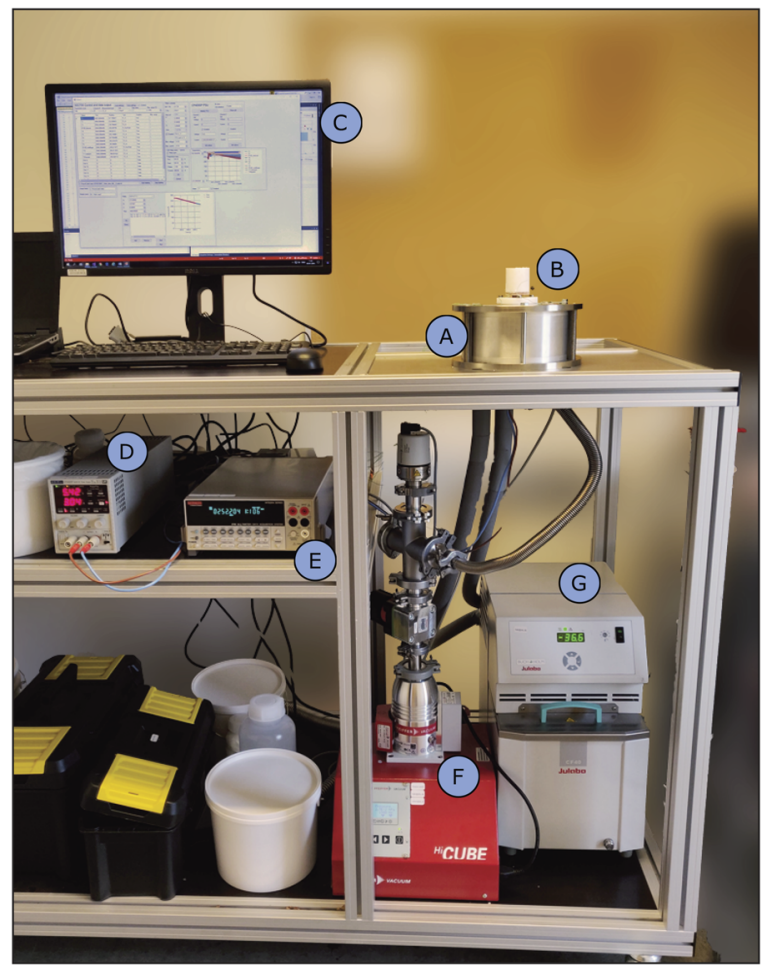

FIG. 1. Full freeze-casting setup. A: vacuum chamber, B: Teflon mold mounted on cold finger, C: PC running control and data logging software, D: power supply, E: Keithley, F: turbo pump, and G: Julabo CF40 chiller.

element (QuickCool QC-127-2.0-15.0 accepting up to $15.5 \mathrm{~V}$ and 15 A) (D). The gap between the cold finger and vacuum chamber is sealed using a Teflon flange (F), and heat is transported away from the Peltier element by using the heat sink (Custom Thermoelectrics WBA-3.0-0.85-CU-01) (C) connected to the Julabo. Tubes for cooling fluids and electronics are attached through port holes (B). The term electronics covers the power supply for the Peltier element and Pt-100 elements $(\mathrm{G})$ attached at both the top of the Peltier element and the top of the cold finger, just inside the vacuum chamber, for precise monitoring and control of temperature.

\section{A. Vacuum sealing and thermal management}

The sealing of the vacuum chamber is carried out with conventional O-ring seals. The critical point of the chamber is the top sealed with a custom Teflon vacuum flange [see Fig. 2(a), (F)]. Here, a radial seal is implemented with tolerances that allow for the $\mathrm{Cu}$ and Teflon parts to shrink as the temperature is decreased. As shown in Table I, the Teflon flange has a much larger coefficient of thermal expansion than $\mathrm{Cu}$; however, as both the $\mathrm{O}$-ring and the Teflon flange are made of materials with very low thermal conductivity, the resulting contraction of the Teflon flange is comparable to or smaller than that of the $\mathrm{Cu}$ rod. As a result, the vacuum holds sufficiently throughout the entire specified temperature range of the device.

The heat exchanger at the bottom of the Peltier element is positioned on a steel-plate (for modest thermal conductivity) that, in turn, is positioned on four legs made of plastic screws, ensuring a large thermal resistance from the heat exchanger to the frame of the vacuum chamber. On top of the Peltier element, a thin Aldisk is installed with the Cu-finger mounted on top. The Al-disk is clamped lightly with plastic screws to the bottom steel plate. The plastic screws ensure flexibility during operation allowing thermal expansion or contraction of the various components. Closeup images of this are available in the supplementary material. Choosing aluminum for the plate on top of the Peltier element is a balance between having a large thermal conductivity and a minimal thermal mass. Furthermore, $\mathrm{Al}$ is easier to machine than $\mathrm{Cu}$. The coldfinger is made of $\mathrm{Cu}$ as the largest possible thermal conductivity is desired. The cooling power of the device is spent on both increasing the temperature gradient across these internal parts and absorbing the latent heat of fusion from the freezing front. Hence, the finger has been made as thin and short as possible given various room requirements in order to ensure that the thermal mass is as small as possible. This ensures (i) a quick response of the system when the temperature is set to be changed and (ii) the ability to reach the lower temperature limit set by the combined Peltier-element and chiller at the top of the $\mathrm{Cu}$-finger as the combined thermal mass of the Aland $\mathrm{Cu}$-components is low relative to the latent heat of fusion at the freezing front. a)

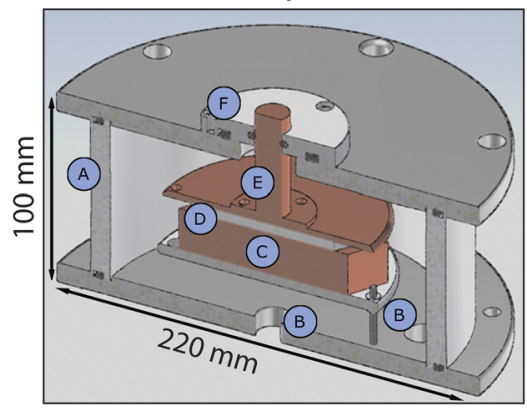

b)

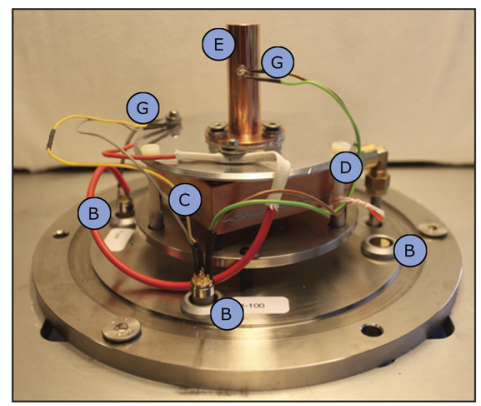

c)

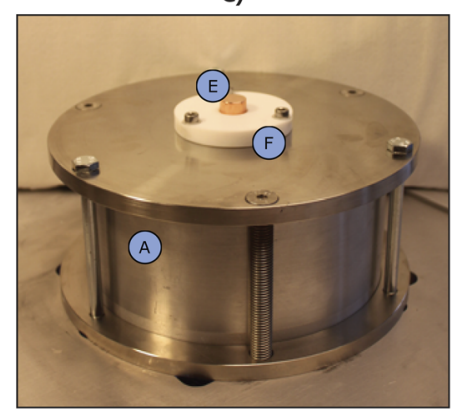

FIG. 2. Zoomed-in view of the freeze-caster. (a) Illustration of the cross-sectional view. (b) The open configuration. (c) The closed configuration. A: vacuum chamber, B: port holes for tubing and electronics, C: heat exchanger, D: Peltier element, E: cold finger, F: Teflon vacuum flange, and G: Pt-100 elements. 
TABLE I. Thermal properties of Teflon, copper, and ice: coefficient of linear thermal expansion, thermal conductivity, and thermal diffusivity, respectively.

\begin{tabular}{lccc}
\hline \hline & $\alpha\left(10^{-6} \mathrm{~K}^{-1}\right)$ & $k\left(\mathrm{Wm}^{-1} \mathrm{~K}^{-1}\right)$ & $\lambda\left(10^{-6} \mathrm{~m}^{2} \mathrm{~s}^{-1}\right)$ \\
\hline Teflon & $112-125$ & 0.250 & 0.124 \\
Copper & 17 & 401 & 111 \\
Ice & 51 & 2.2 & 1.13 \\
\hline \hline
\end{tabular}

\section{B. Molds and temperature tracking}

The mold design for the freeze-caster is interchangeable for high flexibility and various freezing conditions. For the purpose of verifying the setup, a simple, a cylindrical design was chosen. The mold walls are made of Teflon with a detachable copper bottom for optimal thermal conductivity between the sample and cold finger. The Teflon mold and $\mathrm{Cu}$ bottom are assembled using vacuum grease for easy and quick disassembly. The mold is shown in Fig. 3.

Teflon has a very low coefficient of friction easing the demolding of samples. Moreover, the thermal conductivity of Teflon is also very low (see Table I), thermally isolating the freezing sample from the surroundings while not cooling down faster than the sample. This prevents bidirectional freezing, i.e., where the mold walls act as a cooling source as well as the mold bottom.

The thermal contraction of Teflon is larger than that of $\mathrm{Cu}$, which causes an issue with a composite mold of both materials. However, assembling the mold parts using vacuum grease allows the two materials to contract independently without tension. Moreover, the mold is kept open at the top in order to allow room for the water expanding as it transitions into ice.

The mold is equipped with a detachable copper bottom with the primary function of ensuring high thermal conductivity between the freezing sample and the cold finger of the freeze-casting device. A thermocouple insert $(\varnothing 1 \mathrm{~mm} \times 4.5 \mathrm{~mm}$ depth) for temperature monitoring and a circular $3.5 \mathrm{~mm}$ indentation matching the diameter of the cold finger are drilled into the bottom of the $\mathrm{Cu}$ mold-part for easy mounting and demounting of the mold.

As previously mentioned, the freezing rate or freezing front velocity is paramount for the resulting internal dimensions of the
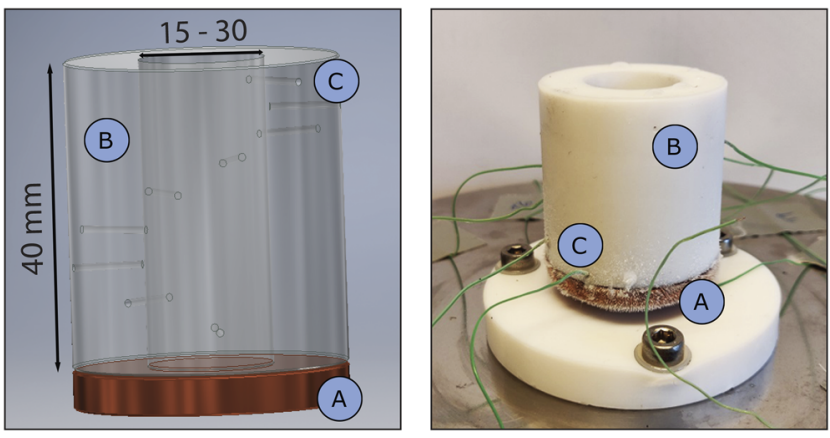

FIG. 3. Cylindrical mold design for the freeze-caster. A: detachable Cu bottom. B cylindrical Teflon mold. C: thermocouple inserts in a helical pattern. freeze-cast structure and temperature control, and monitoring is thus vital in order to evaluate the processing of a freeze-cast structure. Thermocouple inserts $(\varnothing 1 \mathrm{~mm})$ are drilled into the Teflon mold along its height. Inserts are $9.25 \mathrm{~mm}$ deep leaving $0.75 \mathrm{~mm}$ of the Teflon wall between the freezing suspension and the thermocouple, inevitably resulting in a thermal lag with regards to tracking the freezing front position. However, as the lag is assumed to be consistent for all thermocouple positions at equivalent temperatures, this will, in principle, not affect the evaluation of the freezing front velocity, but only provide an offset to the freezing front position with respect to time. Evaluation of the freezing front position is discussed further in Sec. IV A. The thermocouple inserts are placed in a helical pattern along the length of the mold, as shown on Fig. 3(c), with a $4 \mathrm{~mm}$ spatial resolution along the freezing direction. This pattern is thought to ensure that the changes in mold wall thickness and thus boundary conditions of the suspension are distributed radially across the sample to avoid a significant distortion of the freezing front surface due to local changes in wall thickness. Thermocouples type $\mathrm{K}$ are mounted on the inserts with thermal paste to ensure proper thermal conduction.

\section{Implementation of temperature control}

The control software is custom-made in C\# and facilitates a PID (proportional-integral-derivative) controller with a feedback loop for controlling the temperature of the cold finger. The cold finger is equipped with a Pt-100 element just inside the vacuum chamber as close as possible to the freezing sample [see Fig. 2(b), (G)]. The temperature at this position is continuously fed to the software and adjusted according to the PID settings to fit a given set-temperature. The set-temperature can be constant or defined to be a function of time, e.g., a linear function or an exponential function, as has been suggested for obtaining a constant freezing front velocity.

\section{EXPERIMENTAL METHODS}

In order to evaluate the performance and demonstrate the capabilities and limitations of the freeze-caster, samples of water and samples of ceramic suspensions were frozen using various dynamic temperature profiles.

\section{A. Implementation of temperature profiles}

An exponential freezing function was chosen based on the work of Stolze et al. ${ }^{14,15}$ and Flauder et al., ${ }^{13}$ as described below, while constant freezing rates were chosen in the range of -0.5 to $-20 \mathrm{~K} / \mathrm{min}$, resulting in linear temperature profiles. Under equivalent conditions, these freezing rates should yield freeze-cast ceramics with approximate constant channel dimensions in the order of $1-100 \mu \mathrm{m}$. $3,6,8$

Stolze et al. ${ }^{14,15}$ derived and verified an exponential cooling function, Eq. (1), for maintaining a constant freezing front velocity during directional solidification of a ceramic suspension,

$$
f(t)=T_{0}+\frac{H_{f}}{c_{s}}\left(1-\exp \left(\frac{v_{f}^{2}}{\lambda_{s}} t\right)\right) .
$$

Here, subscripts $s$ and $f$ denote the solid and fluid, respectively. $T_{0}$ is the solidification temperature of the suspension, $H_{f}$ is the heat 
TABLE II. Physical properties of water at $273 \mathrm{~K}$; heat of fusion, specific heat capacity, density, and thermal conductivity, respectively.

\begin{tabular}{|c|c|c|c|}
\hline$H_{f}$ & $c$ & $\rho$ & $k$ \\
\hline $333.55 \mathrm{~kJ} \mathrm{~kg}^{-1}$ & $2.108 \mathrm{~kJ}(\mathrm{~kg} \mathrm{~K})^{-1}$ & $920 \mathrm{~kg} \mathrm{~m}^{-3}$ & $2.2 \times 10^{-3} \mathrm{~kW}(\mathrm{~m} \mathrm{~K})^{-1}$ \\
\hline
\end{tabular}

of fusion, $c_{s}$ is the specific heat capacity, and $\lambda_{s}$ is the thermal diffusivity, where the latter is related to the thermal conductivity, $k_{s}$, as follows: $\lambda_{s}=k_{s} / \rho_{s} c_{s}$.

For exponential freezing of water samples, coefficients for the exponential freezing function $f(t)=A+B e^{C t}$ were chosen such that it fulfills Eq. (1) with the physical properties of water at $273 \mathrm{~K}$ listed in Table II and $v_{f}=5 \mu \mathrm{m} / \mathrm{s}, 10 \mu \mathrm{m} / \mathrm{s}, 15 \mu \mathrm{m} / \mathrm{s}$, and $20 \mu \mathrm{m} / \mathrm{s}$, assuming that Eq. (1) also holds true for water alone.

Additionally, Stolze et al. ${ }^{15}$ derived an expression for the maximum obtainable sample height, $L_{\max }$, based on the minimum temperature limit, $f_{\min }$, of a given freeze-casting setup:

$$
L_{\max }=\frac{\lambda_{s}}{v_{f}} \ln \left(1-\frac{c_{s}}{h_{f}}\left(f_{\min }-T_{0}\right)\right) .
$$

\section{B. Freeze-casting}

Samples of ceramic suspensions were frozen using linear temperature profiles, while water samples were frozen using both exponential and linear freezing profiles. In order to avoid significant supercooling of water, tap water containing natural minerals was used.

The preparation of ceramic suspensions for freeze-casting, post-processing of freeze-cast specimens, and structural analysis follows that previously described by Christiansen et al. ${ }^{8,25}$ A ceramic suspension was prepared from 25 vol. \% powders of $\mathrm{La}_{0.67} \mathrm{Ca}_{0.27} \mathrm{Sr}_{0.06} \mathrm{Mn}_{1.05} \mathrm{O}_{3}$ (LCSM, CerPoTech) in MiliQ water, with the addition of $2.5 \mathrm{wt} \%$, relative to the ceramic powder, of DURAMAX $^{\mathrm{TM}}$ D-3005 (Rohm and Haas, Dow Chemical) as the dispersing agent and $2.0 \mathrm{wt}$ \%, relative to the ceramic powder, of DURAMAX $^{\mathrm{TM}}$ B-1022 (Rohm and Haas, Dow Chemical) as the binder. The suspension was mixed using a low energy ball mill for at least $48 \mathrm{~h}$ or until all agglomerates had been eliminated, and a consistent particle size distribution was established as analyzed using a laser diffraction particle size analyser (LS 13 320, Beckman Coulter), reaching a median particle size of $\sim 1.8 \mu \mathrm{m}$.

The water or ceramic suspension and mold were pre-cooled in an ice-bath. The mold was then mounted directly onto the cold finger. The mold was equipped with thermocouples while ensuring sufficient thermal contact by applying thermal paste at the contact interface between the copper bottom and cold finger as well as in the thermocouple inserts.

Meanwhile, bubbles were removed from the ceramic suspension using sonication and the de-aired ceramic suspension or water was transferred to the mold. The mold and sample were encapsulated in $15 \mathrm{~mm}$ insulating foam for tubing and a styrofoam box enclosing both the exposed cold finger and encapsulated freezecasting mold. The temperature inside the styrofoam box, i.e., the ambient conditions during casting, was thus kept below $280 \mathrm{~K}$ at all times. The temperature of the cold finger was kept constant at $275 \mathrm{~K}$ for 5-10 min before applying an either linear or exponential freezing profile. Temperature measurements were obtained until the sample was frozen solid.

Three samples were frozen for each applied temperature profile in order to evaluate the mean and standard deviation of each measurement point.

The frozen ceramic freeze-cast samples were subsequently freeze-dried for at least $24 \mathrm{~h}$ and sintered at $1100{ }^{\circ} \mathrm{C}$ in air for $3 \mathrm{~h}$ (heating rate of $30 \mathrm{~K} / \mathrm{h}$ ), with initial burnout of organics at $250{ }^{\circ} \mathrm{C}$ and $450^{\circ} \mathrm{C}$ (heating rate of $15 \mathrm{~K} / \mathrm{h}$ ). Samples were then infiltrated with epoxy and cut into smaller specimens revealing cross sections for imaging using a scanning-electron microscope (SEM, TM3000, Hitachi High-Technologies). Internal, structural dimensions of freeze-cast samples were estimated by image analysis using a continuous particle size distribution method ${ }^{26}$ as described by Christiansen et al.

\section{RESULTS AND DISCUSSION}

\section{A. Evaluation of freezing conditions and performance}

All temperature curves for samples frozen at various freezing rates showed a few reoccurring characteristics. Considering first the pure water samples, the measured temperature profiles for all thermocouple positions for a sample of water frozen at $-2 \mathrm{~K} / \mathrm{min}$ are shown in Fig. 4(a). Small fluctuations are filtered away by a median filter in MATLAB ${ }^{\circledR}$ and temperature measurements of the thermocouple furthest away from the cold finger is evaluated as in Fig. 4(b).

For all samples of water, a super cooling followed by rapid nucleation resulted in a sudden release of the latent heat, observed as a spike in temperature measurements with a temporal delay along the sample. The spike is indicated by the arrow in Fig. 4(a). This phenomenon was also observed for suspensions of ceramic powders, however, to a much smaller degree, as the powder particulates introduced an extensive number of nucleation sites compared to the water and super cooling were thus significantly less dominating.

For pure water at $1 \mathrm{~atm}$, the freezing point is $273.15 \mathrm{~K}$; however, for tap water and especially for water-based ceramic suspensions with both particulates and organic additives, solute effects will result in freezing point depression, i.e., a decrease in freezing temperature. Thus, $273.15 \mathrm{~K}$ cannot be used as a temperature indicator for the position of the freezing front as the actual freezing point will be lower. However, when looking at the temperature profiles at various thermocouple positions during freezing in Fig. 4, a significant bump in the temperature curve for the thermocouple at $25.5 \mathrm{~mm}$ is evident at $T_{\text {trans }}=271.45 \mathrm{~K}$ with the equivalent time $t_{\text {trans }}=2074.4 \mathrm{~s}$ 
a)

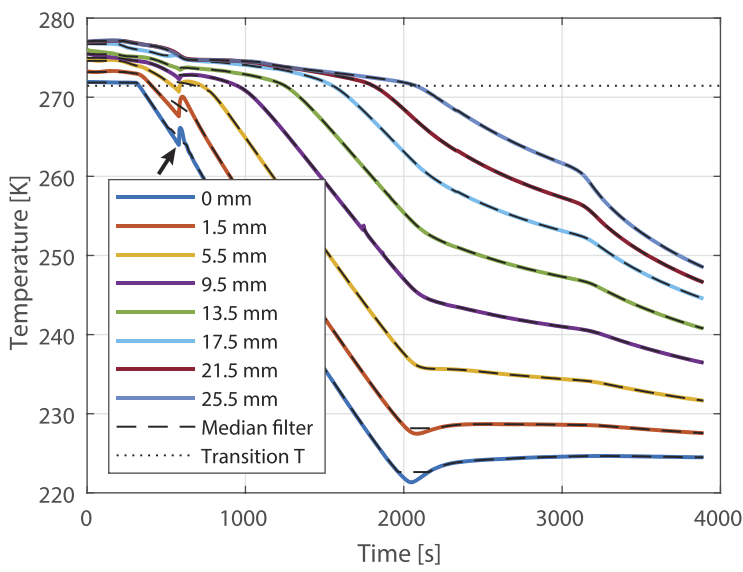

b)

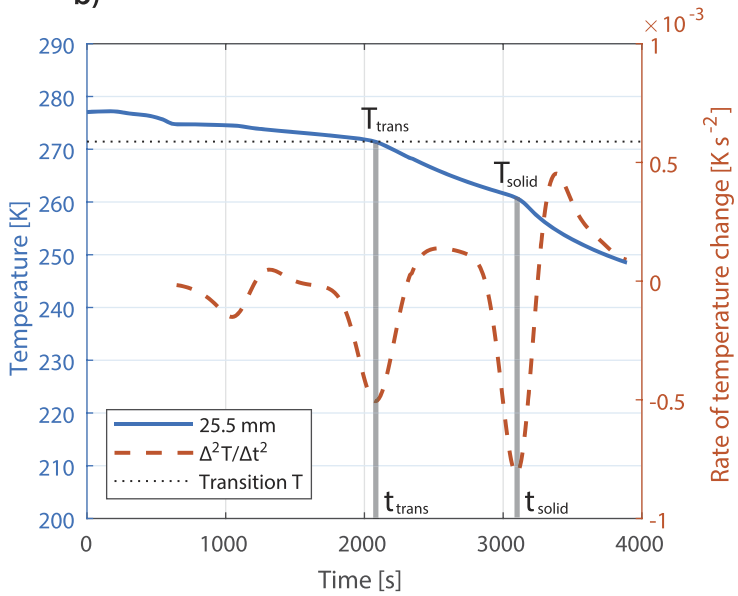

FIG. 4. Temperature measurements at all thermocouple positions as a function of time obtained for a water sample frozen at $-2 \mathrm{~K} / \mathrm{min}$. (a) All temperature measurements are filtered using a median filter in MATLAB ${ }^{\circledR}$. The black arrow indicates the onset of freezing with a spike in temperature due to the release of latent heat upon sudden nucleation in a super cooled sample. (b) The orange curve shows $\frac{\Delta^{2} T}{\Delta t^{2}}$ for the thermocouple positioned at $25.5 \mathrm{~mm}$. From the peak analysis, the change in cooling rate for estimating the freezing temperature, $T_{\text {trans }}$, and thus the freezing front position at $t_{\text {trans }}$ as well as the total freezing time, $t_{\text {solid }}$, of the sample is evaluated.

indicating an increase in the cooling rate. As the thermal conductivity of ice is approximately four times greater than that of water, an increase in cooling rate at a given position is exactly what is expected to occur as the liquid water transitions into ice, and this bump thus indicates the transition temperature, i.e., the freezing temperature for either the water or the ceramic suspension. Therefore, the time at which the freezing front reaches a given thermocouple position can be estimated and thereby the average freezing front velocity between two thermocouple positions can be calculated. Generally, the bump related to the transition temperature can be identified for all thermocouple positions. For practical reasons, the transition temperature is found from the temperature curve for the thermocouple furthest away from the cold finger when freezing kinetics are evaluated for frozen samples in Sec. IV A 1.

In Fig. 4(b), the second bump at time $t_{\text {solid, }}$ evident at all thermocouple positions at the same time, indicates an increase in the cooling rate of the sample when it has completely transitioned into ice, and no more latent heat is released in the system. $t_{\text {solid }}$ is thus the total freezing time.

In the case of samples frozen at $-2 \mathrm{~K} / \mathrm{min}$, the time, $t_{\text {trans }}$, at which the thermocouple at the top of the mold reaches $T_{\text {trans }}$ coincides with that of the cold finger reaching the minimum temperature of the freeze-caster. $25.5 \mathrm{~mm}$ sample height is thus close to the capacity of the freeze-caster for samples of water frozen at this temperature profile, as the temperature of the cold finger beyond $t_{\text {trans }}$ no longer follows the preset temperature profile. This is illustrated in Fig. 5, where the absolute value of the offset temperature is seen to significantly increase beyond $2000 \mathrm{~s}$. The current minimum temperature of $\sim 220 \mathrm{~K}$ of the current freeze-casting device can be decreased by replacing the thermoelectric element with a multi-module thermoelectric element by equipping the device with chillers in series or simply by replacing the Julabo chiller with a chiller of lower minimum temperature. Decreasing the operational temperature of the freeze-casting device will increase the achievable sample height for freeze-cast samples.

Furthermore, the current maximum temperature of the freezecasting device is defined by the maximum operational temperature of the Peltier element of $440 \mathrm{~K}$, making it also suitable for freezecasting of suspensions with alternative fluids such as camphene ${ }^{21}$ or tert-butyl alcohol, ${ }^{19}$ with solidification temperatures of $325 \mathrm{~K}$ and $298 \mathrm{~K}$, respectively. Both are well within the operational temperature span of the freeze-casting setup presented here.

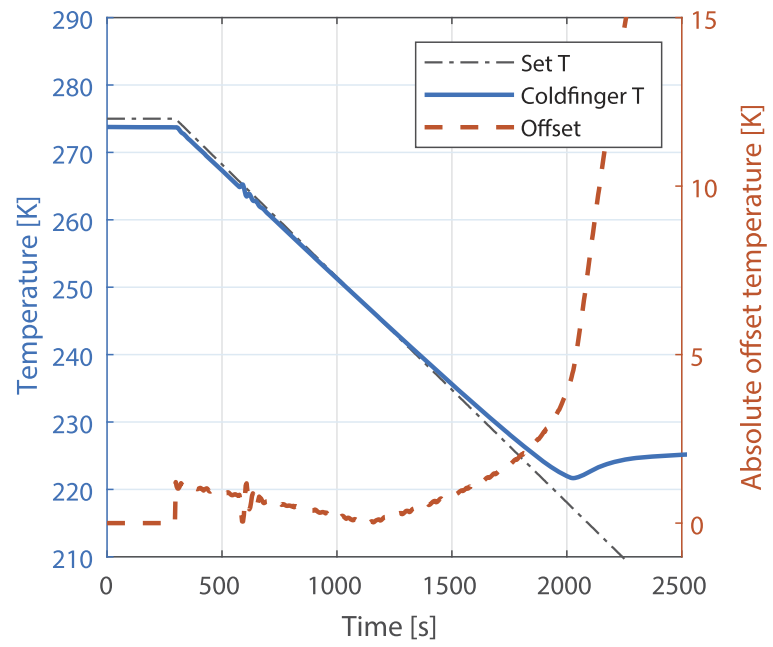

FIG. 5. Cold finger and preset temperature as a function of time for the water sample frozen at a constant freezing rate of $-2 \mathrm{~K} / \mathrm{min}$. Eventually, the cold finger reaches the minimum temperature of the freeze-caster in its current configuration, and the absolute offset temperature, i.e., the temperature difference between the two, significantly increases. 


\section{Linear and exponential freezing profiles}

By evaluating measured temperature curves as described in Sec. IV A, the capacity of the freeze-caster can be evaluated for various dynamic freezing profiles. Estimated freezing front velocities and maximum heights for water samples are given in Fig. 6 for both linear freezing profiles $[(a)$ and (b)] and exponential freezing profiles $[(\mathrm{c})$ and $(\mathrm{d})]$.

As the bottom part of the suspensions typically underwent super cooling followed by sudden nucleation, as previously discussed and indicated by the arrow on Fig. 4(a), large deviations of freezing front velocities were found for velocities estimated close to the copper bottom. Only freezing front velocities from a distance of $7.5 \mathrm{~mm}$ from the copper bottom are thus plotted on Figs. 6(a) and $6(\mathrm{c})$.

As previously discussed, $t_{\text {solid }}$ indicates the time at which the sample is completely frozen. For higher freezing rates, this occurs after the cold finger has reached the minimum temperature of the setup. The maximum height in Figs. 6(b) and 6(d) is thus estimated as the height of the frozen part of a freezing sample at the time where the offset between the temperature of the cold finger and the preset temperature profile exceeds $3 \mathrm{~K}$ and is thus the maximum sample length that can be achieved at a given temperature profile. Moreover, for exponentially frozen samples [Figs. 6(b) and 6(d)], maximum a)

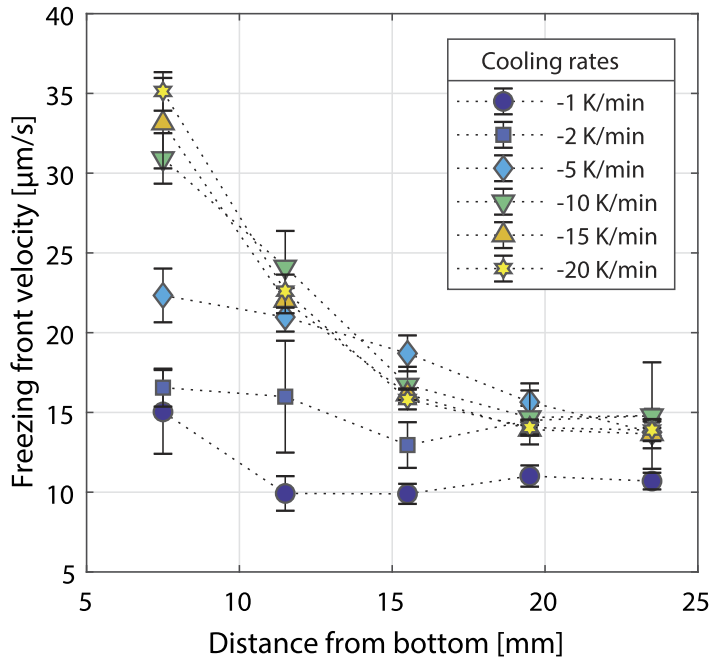

b)

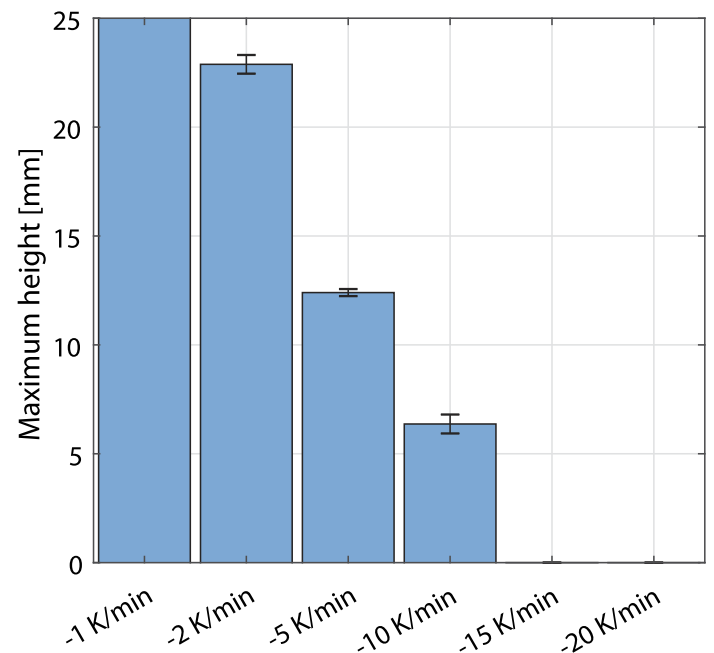

Linear freezing profiles

c)

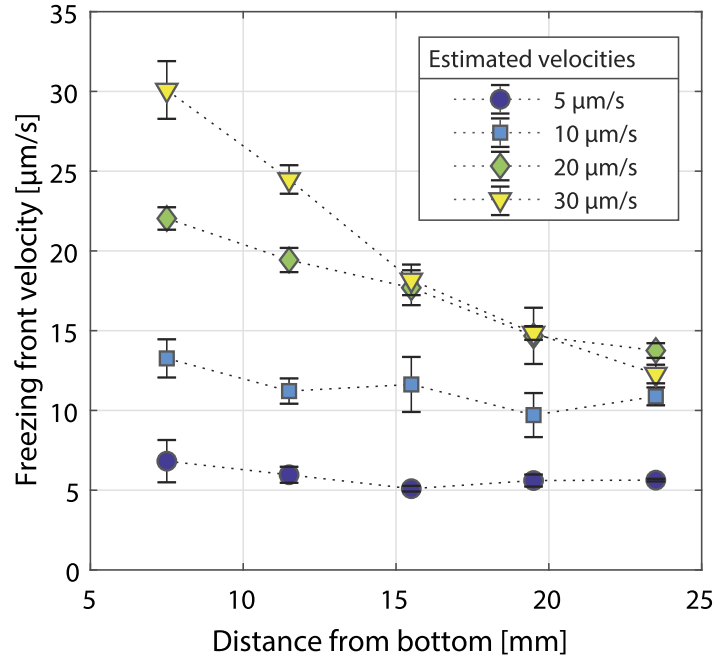

d)

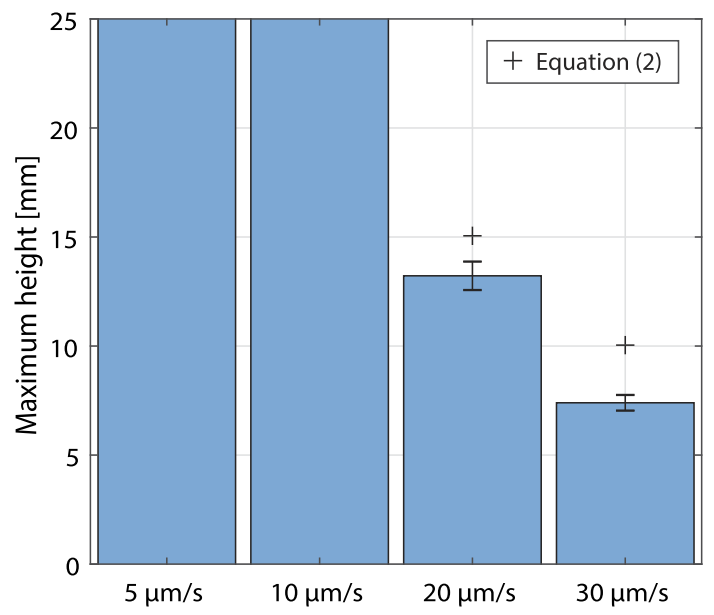

FIG. 6. Evaluated freezing front velocities and estimated maximum height based on $\left|T_{\text {offset }}\right|<3 \mathrm{~K}$ for water samples frozen using linear [(a) and (b)] or exponential [(c) and (d)] temperature profiles. Note that an indicated maximum sample height of $25 \mathrm{~mm}$ in (b) and (d) is merely the maximum measurable height. Actual maximum sample heights are assumed greater. In (d), the maximum obtainable sample heights calculated from Eq. (2) are indicated. 
obtainable heights from Eq. (2) are also indicated. For the estimated freezing-front velocities of $20 \mu \mathrm{m} / \mathrm{s}$ and $30 \mu \mathrm{m} / \mathrm{s}, L_{\max }$ was calculated as $15.07 \mathrm{~mm}$ and $10.05 \mathrm{~mm}$, respectively, which is more or less in accordance with the actual achievable sample heights considering that a degree of thermal loss is expected. Additionally, for $5 \mu \mathrm{m} / \mathrm{s}$ and $10 \mu \mathrm{m} / \mathrm{s}, L_{\max }$ was calculated from Eq. (2) as $60.27 \mathrm{~mm}$ and $30.14 \mathrm{~mm}$, respectively, which are, accordingly, well beyond our required $25 \mathrm{~mm}$.

For the purpose of freeze-casting where a constant freezing front velocity throughout a specific sample length is desired, only linear freezing profiles with cooling rates of $-1 \mathrm{~K} / \mathrm{min}$ and $-2 \mathrm{~K} / \mathrm{min}$ or exponential freezing profiles with estimated velocities of $5 \mu \mathrm{m} / \mathrm{s}$ and $10 \mu \mathrm{m} / \mathrm{s}$ met these criteria. Regarding the latter, samples of estimated freezing front velocities of $5 \mu \mathrm{m} / \mathrm{s}$ and $10 \mu \mathrm{m} / \mathrm{s}$ almost matched the measured actual freezing front velocities, validating Eq. (1). Additionally, applying exponential temperature profiles vs linear temperature profiles appears to have slight influence on the consistency of the freezing front velocity throughout the samples; however, a larger sample batch is required to fully confirm this assumption.

From Fig. 6, it appears that the maximum freezing front velocity maintainable over the length of a $25 \mathrm{~mm}$ sample is $\sim 15 \mu \mathrm{m} / \mathrm{s}$ for the current freeze-caster configuration. As less latent heat will have to be removed during freezing from a ceramic suspension as a given volume fraction is substituted with ceramic powder, it is expected that the maximum freezing front velocity would be slightly greater for a ceramic suspension.
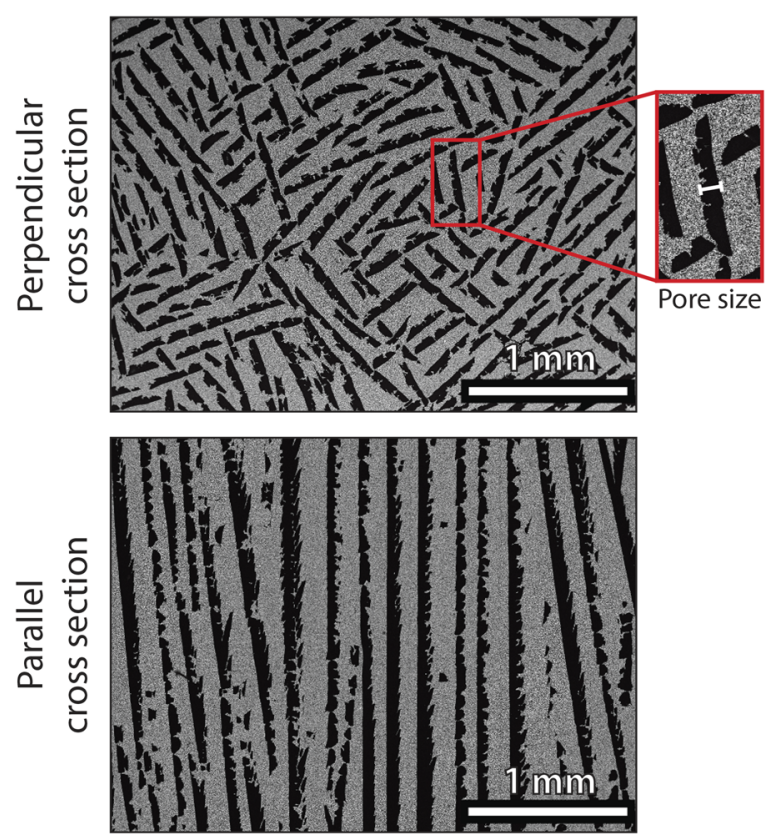

FIG. 7. SEM micrographs of a freeze-cast LCSM ceramic, where gray areas are ceramic walls, while black voids are micro-channels. Images are obtained on cross sections perpendicular or parallel to the freezing direction at a sample height of $12 \mathrm{~mm} \pm 1 \mathrm{~mm}$. The sample was frozen dynamically at a freezing rate of $-1.5 \mathrm{~K} / \mathrm{min}$. Zoomed-in view indicates 'pore size' as plotted in Fig. 8.
The capacity of the current freeze-caster setup could be improved by replacing the chiller, allowing for greater freezing front velocities and larger samples. The setup presented here is prepared for liquid nitrogen as a cooling fluid if larger cooling rates capacities are needed in the future.

\section{Implementation of feedback mechanism}

The current freeze-caster configuration allows for the implementation of various dynamic temperature functions for the temperature of the cold finger during freeze-casting. These can be derived from modeling, experimental data, or empirical knowledge. A possible future upgrade of the freeze-casting device presented is to implement a direct feedback loop while freezing. Monitoring the freezing front with an appropriate temporal and spatial resolution while continuously adjusting the set temperature could enhance the accuracy of reaching the desired temperature profile.

\section{B. Freeze-cast ceramics}

Freeze-casting of LCSM suspensions followed by sublimation and sintering results in ceramic structures of directional porosity in the form of well-defined macropores-or microchannels-running parallel to the freezing direction, as illustrated in Fig. 7. The channels are the inverse imprint of the frozen fluid crystals, however, to some degree altered due to post-processing, i.e., sublimation of ice and sintering.

The channels are lamellar in shape with an ellipsoidal cross section. Channels are ordered in domains of different orientations in the perpendicular cross section. A simple re-design of the mold allowing for bidirectional freezing according to Bai et al. ${ }^{16}$ or $\mathrm{Hu}$ et al. ${ }^{17}$ could ensure an alignment of domains in the perpendicular cross section. The width of the channels or pore size, as defined in

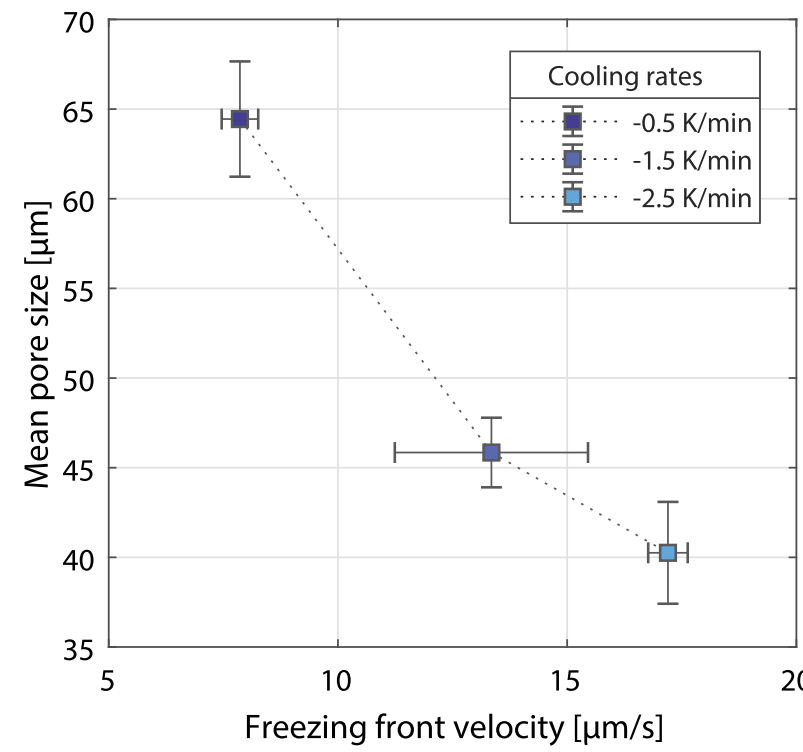

FIG. 8. Mean pore size as a function of freezing front velocity. The freezing front velocity depends on the freezing rate indicated in the legend. The faster the freezing front velocity, the smaller the resulting pore size. 
Fig. 7 in the zoomed-in view, can be determined by image analysis. Mean pore sizes are estimated from 12 SEM micrographs obtained on cross sections parallel to the channel orientation at four sample heights evenly distributed throughout the sintered samples, as described previously. ${ }^{8,25}$ Mean pore sizes as a function of freezing front velocity for samples frozen using various linear freezing profiles are given in Fig. 8 with corresponding cooling rates in the legend. Both the pore size and freezing front velocity are averaged over a sample height of $7.5 \mathrm{~mm}-20 \mathrm{~mm}$.

As is evident from Fig. 8, the mean pore size of the sintered ceramic strongly depends on the freezing front velocity, which decreases in size with an increase in freezing rate, achieving channel widths in the range $\sim 40-65 \mu \mathrm{m}$. This range of pore sizes reflects the experimental conditions and material system of the present study; however, the tendency of increasing pore size with decreasing freezing front velocity is general for freeze-cast materials. $^{11}$

\section{CONCLUSION}

A freeze-casting device utilizing a thermoelectric element for high precision temperature control for implementation of dynamic freezing conditions was presented.

The performance of the device was evaluated by directional freezing of water and aqueous ceramic suspension samples using both linear and exponential freezing profiles. The freezing front was successfully tracked by measuring the temperature gradient along the sample using thermocouples directly mounted on the freezecasting mold. The maximum freezing front velocity maintainable over the length of a $25 \mathrm{~mm}$ sample was $\sim 15 \mu \mathrm{m} / \mathrm{s}$ for the current freeze-caster configuration.

Implementing linear freezing profiles with cooling rates of $-0.5 \mathrm{~K} / \mathrm{min}$ to $-2 \mathrm{~K} / \mathrm{min}$ resulted in LCSM ceramic with lamellar microchannels with pore widths of $\sim 40 \mu \mathrm{m}$ to $\sim 75 \mu \mathrm{m}$.

The current operational temperature range of the freeze-caster is $\sim 220-440 \mathrm{~K}$. The performance and capacity of the freeze-casting device can be enhanced by the implementation of (i) a direct feedback loop for immediate adjustment of the freezing profile and (ii) liquid nitrogen as cooling fluid.

\section{SUPPLEMENTARY MATERIAL}

See the supplementary material for the code for temperature control software available at GitHub: github.com/cmt-dtuenergy/ControlSoftware/tree/master/FreezeCasterInterface. Work drawings and additional closeup images are available at DTU Data, DOI: 10.11583/DTU.11799801.

\section{ACKNOWLEDGMENTS}

This work was funded by the Independent Research Fund Denmark-Technologies and Productions Sciences (Project No. 6111-00073B).

\section{REFERENCES}

${ }^{1}$ U. G. K. Wegst, M. Schecter, A. E. Donius, and P. M. Hunger, Philos. Trans. R. Soc. A 368(1917), 2099 (2010).

${ }^{2}$ J. Seuba, S. Deville, C. Guizard, and A. J. Stevenson, Sci. Technol. Adv. Mater. 17, 313 (2016).

${ }^{3}$ A. Z. Lichtner, D. Jauffrès, C. L. Martin, and R. K. Bordia, J. Am. Ceram. Soc. 96 2745 (2013).

${ }^{4}$ J. Gurauskis, C. R. Graves, R. Moreno, and M. I. Nieto, J. Eur. Ceram. Soc. 37, 697 (2017).

${ }^{5}$ S. Deville, Scr. Mater. 147, 119 (2018).

${ }^{6}$ S. Deville, E. Saiz, and A. P. Tomsia, Acta Mater. 55, 1965 (2007).

${ }^{7}$ T. Waschkies, R. Oberacker, and M. J. Hoffmann, J. Am. Ceram. Soc. 92, S79 (2009).

${ }^{8}$ C. D. Christiansen, K. K. Nielsen, R. K. Bordia, and R. Bjørk, J. Am. Ceram. Soc. 102, 5796 (2019).

${ }^{9}$ S. Deville, E. Maire, A. Lasalle, A. Bogner, C. Gauthier, J. Leloup, and C. Guizard, J. Am. Ceram. Soc. 92, 2489 (2009).

${ }^{10}$ A. Bareggi, E. Maire, A. Lasalle, and S. Deville, J. Am. Ceram. Soc. 94, 3570 (2011).

${ }^{11}$ K. L. Scotti and D. C. Dunand, Prog. Mater. Sci. 94, 243 (2018).

${ }^{12}$ T. Waschkies, R. Oberacker, and M. J. Hoffmann, Acta Mater. 59, 5135 (2011).

${ }^{13}$ S. Flauder, U. Gbureck, and F. A. Müller, Acta Biomater. 10, 5148 (2014).

${ }^{14}$ C. Stolze, T. Janoschka, S. Flauder, F. A. Müller, M. D. Hager, and U. S. Schubert, ACS Appl. Mater. Interfaces 8, 23614 (2016).

${ }^{15}$ C. Stolze, T. Janoschka, U. S. Schubert, F. A. Müller, and S. Flauder, Adv. Eng. Mater. 18, 111 (2016).

${ }^{16}$ H. Bai, Y. Chen, B. Delattre, A. P. Tomsia, and R. O. Ritchie, Sci. Adv. 1, e1500849 (2015).

${ }^{17}$ Z. Hu, X. Shen, S. Geng, P. Shen, and Q. Jiang, Ceram. Int. 44, 5803 (2018).

${ }^{18}$ J. Seuba, J. Leloup, S. Richaud, S. Deville, C. Guizard, and A. J. Stevenson, J. Eur. Ceram. Soc. 37, 2423 (2017).

${ }^{19}$ Y. Tang, S. Qiu, Q. Miao, and C. Wu, J. Eur. Ceram. Soc. 36, 1233 (2016).

${ }^{20}$ S. W. Sofie, J. Am. Ceram. Soc. 90, 2024 (2007).

${ }^{21}$ S. M. Miller, X. Xiao, and K. T. Faber, J. Eur. Ceram. Soc. 35, 3595 (2015).

${ }^{22}$ N. Arai and K. T. Faber, Scr. Mater. 162, 72 (2019).

${ }^{23}$ C. D. Christiansen, K. K. Nielsen, and R. Bjørk, "Freeze-casting to create create directional micro-channels in regenerators for magnetic refrigeration," in Proceedings of TherMag VIII, 8th IIF-IIR International Conference on Caloric Cooling (Technische Universität Darmstadt, Darmstadt, Germany, 2018), pp. 96-101.

${ }^{24}$ A. Z. Lichtner, "Anisotropic and hierarchical porosity in multifunctional ceramics,” Ph.D. Dissertation (University of Washington, 2015).

${ }^{25}$ C. D. Christiansen, K. K. Nielsen, and R. Bjørk, J. Eur. Ceram. Soc. 40(4), 1398 (2020).

${ }^{26}$ P. S. Jørgensen, S. L. Ebbehøj, and A. Hauch, J. Power Sources 279, 686 (2015). 